\title{
Comparative Analyses of Volatile Metabolites Associated With Gene Expression From Non- climacteric and Climacteric Melon.
}

\section{Kamila Karoline de Souza Los}

UEPG: Universidade Estadual de Ponta Grossa

Michelle Orane Schemberger

UEPG: Universidade Estadual de Ponta Grossa

\section{Leticia Reis}

UEPG: Universidade Estadual de Ponta Grossa

\section{Marília Aparecida Stroka}

UEPG: Universidade Estadual de Ponta Grossa

\section{Caroline Weigert Galvão}

UEPG: Universidade Estadual de Ponta Grossa

\section{Rafael Mazer Etto}

UEPG: Universidade Estadual de Ponta Grossa

Charles F. Forney

Kentville Research and Development Centre

\section{Daniele Santos Domingues}

UEPG: Universidade Estadual de Ponta Grossa

Mariana Celano Menezes de Almeida

UEPG: Universidade Estadual de Ponta Grossa

Ricardo Antonio Ayub ( $\nabla$ ricoayub@gmail.com )

Universidade Estadual de Ponta Grossa https://orcid.org/0000-0003-3240-8417

\section{Research Article}

Keywords: Aroma, amino acid, Climacteric, Non-climacteric, Volatiles, Fruit

Posted Date: August 30th, 2021

DOl: https://doi.org/10.21203/rs.3.rs-831571/v1

License: (c) (i) This work is licensed under a Creative Commons Attribution 4.0 International License.

Read Full License 


\section{Abstract}

Melon (Cucumis melo L.) is an important species in the cucurbits family with a large economic importance in the world. Two melon cultivars commercially important in Brazil are the cultivars 'Yellow' and 'Gaúcho'. In addition to the economic importance, these two cultivars display phenotypic differences in aroma, a major trait determining fruit quality. Volatile organic compounds (VOC) impart the different aroma found in these fruit and its biosynthesis is associated with fatty acid and amino acid metabolism. Using SPME-GC-MS and RT-qPCR techniques, volatile production and expression of seven genes (CmLOX9, CmLOX18, CmBCAT1, CmArAT1, CmPDC1, CmADH1 and CmAAT1) were determined during maturation and ripening. The climacteric melon 'Gaúcho' had a greater number and higher concentration of volatiles than that in the non-climacteric 'Yellow' melon. 2-Methylallyl acetate, 4-amino-1-butanol, 2methylbutanol and ethyl 2-methylpropanoate were found in high concentrations in ripe climacteric 'Gaúcho' melons and were major contributors to its strong fruity aroma, but high concentrations of these volatiles were not found in non-climacteric 'Yellow' melons. The lipid pathway played a strong role in determining aroma composition in non-climacteric 'Yellow' melons. Most volatiles decreased during maturation and ripening explaining the non-aromatic characteristic of this cultivar. In climacteric 'Gaúcho' melons, the amino acid pathway was the main one related to the biosynthesis of esters, which contribute to the aroma of this cultivar. Volatile products of the branched chain amino acid pathway correlated with $\mathrm{CmADH} 1$ and $C m A A T 1$ expression demonstrating their role in volatile synthesis of this climacteric melon cultivar. In addition, CmPDC1 contributes to the formation of aldehydes at the beginning of this pathway.

\section{Key Message}

Lipid pathway was primarily expressed in non-climacteric 'Yellow' fruit aroma formation, in that almost all metabolites decreased during maturation explaining the non-aromatic characteristic of this cultivar. In climacteric 'Gaúcho' melons the amino acid pathway was the primary one related to the biosynthesis of esters. The branched amino acid pathway correlated with $\mathrm{CmADH1}$ and $\mathrm{CmAAT1}$ expression demonstrating integration between them.

\section{Introduction}

Melon (Cucumis melo L.) is an important species in the cucurbits family with 40 million tons of fruit produced globally in 2018 (FAO 2018). Melon (Cucumis melo L.) is an important species in the cucurbits family with 40 million tons of fruit produced globally in 2018 (FAO 2018). Brazil ranks thirteenth as a melon producer with 'Yellow' melons being the most important fresh fruit exported by the country'. Gaúcho melon is a climacteric variety largely appreciated in the South of Brazil having a good adaptability for production in this region (Bissacotti and Londero 2017).

Melon fruit exhibit a wide diversity of phenotypic traits including its ripening physiology. Unlike most plant species, genotypes of melon can express either climacteric (ripening associated with an increase in respiration and ethylene synthesis) or non-climacteric (ripening without an increase in respiration or 
ethylene) ripening (Pitrat et al. 2000; Paris et al. 2016). Ripening involves complex biochemical processes that determine fruit quality characteristics such as color, sweetness, acidity, firmness and aroma (White 2002). Aroma is an important organoleptic trait characterized by a unique combinations of volatile compounds determined by the genetics of the melon cultivar (Schwab et al. 2008; Gonda et al. 2010).

Climacteric melon fruit are more aromatic than non-climacteric ones, producing high concentrations of total volatiles with esters being the most abundant compounds (Gonda et al. 2016), The main pathways of aroma formation involve fatty acid and amino acid metabolism (Fig. 1). Ketones and terpenoids also have a minor role in melon aroma (Flores et al. 2002).

In fatty acid catabolism, lipoxygenases (LOXs) degrade the fatty acids linoleic and a-linolenic acids to form hydroperoxides, which then form aroma compounds (Vincenti et al. 2019). Based on the specific oxygenation position, LOXs are divided into three types: 9-LOX, oxygenation occurs at carbon 9; 13-LOX, oxygenation occurs at carbon 13; and 9/13-LOX, oxygenation can occur at both carbon 9 and carbon 13 of the fatty acid substrate. Depending on which carbon was oxygenated, the hydroperoxide resulting from this reaction can be a 9-hydroperoxide or a 13-hydroperoxide (Feussner and Wasternack 2002). According to Zhang et al. (2010), 9-LOXs are associated with the formation of (3Z)-nonenal, (2E) -nonenol, (Z,Z) 3,6nonadienal and $(E, Z)$ 2,6-nonadienal, which are volatile products commonly largely expressed in plants (Vincenti et al. 2019). 13-LOXs on the other hand are related to the formation of (Z) -3-hexanal and (Z) -3hexenol and their derivatives.

In the amino acid pathway, VOCs are derived mainly from five amino acids, two aromatics, Lphenylalanine and L-methionine, and three branched-chain, L-valine, L-leucine and L-isoleucine (Gonda et al. 2010). The initial stage of this pathway involves a transamination of the amino acid through the activity of branched chain amino transferases (BCATs) on branched chain amino acids or aromatic aminotransferases (ArATs) on aromatic amino acids (Gonda et al. 2016). The volatiles formed in the branched chain amino acid pathway are 2-methylbutanal, 3-methylbutanal, 2-methylpropanal and their related alcohols and esters (Gonda et al. 2016). As for the aromatic amino acid pathway important volatiles formed are phenylacetaldehyde and its related esters (Gonda et al. 2016).

Another prominent enzyme in melon fruit is pyruvate decarboxylase (PDC) that is associated with the decarboxylation of keto-acids generating pentanal and propanal and consequently their derivatives (Wang et al. 2019). In the final steps of volatile biosynthesis, alcohol dehydrogenase (ADH) and alcohol acyl transferase (AAT) are key enzymes that convert aldehydes into alcohols and esters. In melon aroma, aldehydes and alcohols often display green, leafy, cucumber-like notes, while esters are related to the emission of fresh, floral, fruity notes (Gonda et al. 2016).

Considering the importance of aroma volatiles in the overall flavor of fruit, integrative studies relating metabolomics and gene expression data are crucial to better understand the organoleptic profile of the wide phenotypic diversity of melons, as well as, the biochemical complexity involved in aroma production. Thus the aim of this study was to identify volatile compounds specific to climacteric and 
non-climacteric ripening in melons ('Gaúcho' and 'Yellow' respectively) and associate volatile production with the transcription of genes that encode enzymes of fatty acid and amino acid metabolic pathways.

\section{Material And Methods}

\section{Plant Material}

For volatile analysis, melon fruit ( $C$. melo cv Yellow and Gaúcho) were grown in a greenhouse at the Kentville Research and Development Centre, Agriculture and Agri-Food Canada (Kentville, Nova Scotia, Canada) in the summer of 2017. For the qRT-PCR analysis fruit from the same cultivars were grown under the same greenhouse conditions at Ponta Grossa State University - UEPG (Ponta Grossa, Paraná, Brazil) in the summer of 2018. In both locations fruit were harvested at 15, 25, 35 and 45 days after pollination (DAP) (Supplementary Fig. 1). For volatiles, fruit at 15, 25, 35 and 45 DAP were analyzed, whereas for qRT-PCR only fruit at 35 and 45 DAP were analyzed

Peel and pulp color; soluble solids content (SSC) and pH.

Three fresh fruit from each cultivar, grown in both Canada and Brazil, were measured for peel and pulp color at different ripening stages using a Minolta CR400 colorimeter. The CIE (Commission Internationale de l'Eclairage) L* (lightness), a* (green/red coordinate), b* (blue/yellow coordinate) color scale was used. Hue angle was calculated using the equation $h^{\circ}=\tan ^{-1}\left(b^{*} / a^{*}\right)$, when $a^{*}>0$ and $b^{*}>0$ or $h^{\circ}=180+\tan ^{-}$ ${ }^{1}\left(b^{\star} / a^{*}\right)$, when $a^{*}<0$ or $b^{*}>0$ (MCLELLAN et al. 1995). Soluble solids content (SS ${ }^{\circ}$ Brix) and the $\mathrm{pH}$ were measured using a digital refractometer and automatic $\mathrm{pH}$ meter respectively. Three measurements were made for each fruit and a mean was calculated.

\section{Volatile analysis}

For each maturity stage for both cultivars, $20 \mathrm{~g}$ of a composite frozen sample $\left(-80^{\circ} \mathrm{C}\right)$ from fruit mesocarp were blended in $20 \mathrm{~g}$ of a saturated salt solution $(\mathrm{NaCl})$ for $1 \mathrm{~min}$. A $10 \mathrm{~g}$ sample was then placed in a $20 \mathrm{~mL}$ headspace vial, capped and $5 \mathrm{uL}$ of an internal standard mix ( $9.8 \mathrm{mg} \mathrm{L}^{-1}$ Ethyl acetated8; $10.0 \mathrm{mg} \mathrm{L}^{-1}$ benzaldehyde-d6; $10.2 \mathrm{mg} \mathrm{L}^{-1}$ 2-phenyl-d5-ethanol; $8.2 \mathrm{mg} \mathrm{L}^{-1}$ 2-hexanone-d5) was added. The volatile compounds were extracted and analyzed by solid phase micro extraction-2D gas chromatography-mass spectroscopy (SPME-GCxGC-MS) using a Pegasus 4D GCxGC-TOFMS system (LECO, St. Joseph, MI, USA). Vials were incubated at $50^{\circ} \mathrm{C}$ for 300 s and then the divinylbenzene/Carboxen/polydimethylsiloxane SPME fiber (Supelco Analytical, Bellefonte, PA, USA) was exposed to the headspace for $900 \mathrm{~s}$ with agitation (on for 60 seconds; off for 1 second). The fiber was desorbed at $250^{\circ} \mathrm{C}$ for $15 \mathrm{~min}$. The injector was operated at $250^{\circ} \mathrm{C}$ in the split mode of $1: 20$ for $1 \mathrm{~min}$. Helium was used as the carrier gas at a flow rate of $1.4 \mathrm{~mL} / \mathrm{min}$.

To achieve 2 dimensional GC analysis, a quad-jet dual stage thermal modulator that was cooled with liquid nitrogen, was mounted in a secondary oven in an Agilent $7890 \mathrm{GC}$ gas chromatograph. The first dimension (1D) column was a polar Stabilwax ${ }^{\circledR}(30 \mathrm{~m} \times 0.25 \mathrm{~mm} \times 0.25 \mu \mathrm{m})$, and the second dimension 
(2D) column was a mid-polar Rxi®-5Sil MS $(0.30 \mathrm{~m} \times 0.25 \mathrm{~mm} \times 0.25 \mu \mathrm{m})$. The optimized 1D GC oven temperature was initially set at $50^{\circ} \mathrm{C}$ for $0.20 \mathrm{~min}$, before being increased at $10.3^{\circ} \mathrm{C} / \mathrm{min}$ to $220^{\circ} \mathrm{C}$. The temperature offset for the secondary oven was $44 \circ \mathrm{C}$. The modulation period (PM) was $1.1 \mathrm{~s}$, with a hot pulse time of $0.33 \mathrm{~s}$ on each jet. The transfer line was held at $250^{\circ} \mathrm{C}$. The TOF-MS was operated in electron ionization (EI) mode at $70 \mathrm{eV}$, with an acquisition mass range of 35-300 amu, an acquisition rate of $200 \mathrm{~Hz}$, and a detector voltage of $1500 \mathrm{~V}$ with an optimized voltage of $200 \mathrm{~V}$. The ion source was heated to $250^{\circ} \mathrm{C}$. Daily mass calibration and tuning were performed using perfluorotributylamine (PFTBA). An acquisition delay of $100 \mathrm{~s}$ was applied.

The chemical identification of the peaks was determined based on the retention index and correspondence of the mass spectrum with the National Institute of Standards and Technology (NIST) Mass Spectral virtual Library (ChemSW, Fairfield, CA, USA) and possible identifications were confirmed with known standards when available. To calculate total ion counts (TIC) of each compound the LECO APEX data deconvolution/processing routine was used. Area counts were normalized against the internal standard 2-hexanone-d5.

\section{Quantitative reverse transcription PCR analysis (qRT-PCR Analysis)}

Total RNA was isolated from fruit mesocarp in biological triplicate using the sodium perchlorate method as described by Campos et al., (2017). Once isolated, RNA samples were submitted to the TURBO ${ }^{\text {TM }}$ DNase kit (Invitrogen) at $37^{\circ} \mathrm{C}$ for 30 min to remove genomic DNA. Then RNA samples that presented high quality were converted to cDNA using the High-Capacity cDNA Reverse Transcription Kit (Applied Biosystems) according to manufacturer's instructions.

The primers used and their respective oligonucleotide sequences are represented in Supplementary Table 1. A $60 \mathrm{ng}$ sample of cDNA was used for each qRT-PCR reaction. Thermocycling was initiated with a 15 min incubation at $95^{\circ} \mathrm{C}$, followed by 40 cycles $\left(95^{\circ} \mathrm{C}, 15 \mathrm{~s}\right.$; primer specific temperature (Supplementary Table 1 ), $72^{\circ} \mathrm{C} 20 \mathrm{~s}$ ). The relative quantification for gene expression was achieved using the housekeeping Ribosomal protein S15 (CmRPS15) and 60s Ribosomal protein L (CmRPL) genes according to Kong et al. (2014). The analyses were performed in an AriaMx Real-Time PCR System (Agilent) and expression values were calculated using Livak and Schmittgen, (2001) Eq. $2^{-\Delta \Delta C t}$.

\section{Statistical analyses}

The volatile data analyses were performed using ANOVA with orthogonal contrasts, and PCA through Genstat 16 (VSN International, 2013) software. To infer a significance in the gene expression analysis for the different cultivars and stages the values obtained by the equation of Livak and Schmittgen, (2001) were submitted to an ANOVA using the $R$ statistics environment ( $R$ Team, 2010). Values considered significant were those that presented a $p$-value $<0.05$.

Metabolites versus metabolites, gene expression versus genes expression and gene expression versus metabolites correlations were calculated using Pearson correlation and the results were visualized using 
the corrplot package (Wei et al. 2017).

\section{Results}

\section{Phenotypic characterization}

Melon maturity at different days after pollination (DAP) was assessed by measuring color, solids soluble content (SSC) and pH of the two types of melon fruit grown in both regions (Brazil and Canada).

Colorimeters express color in numerical terms (see methods) along the $L^{*}, a^{*}$ and $b^{*}$ axes (from white to black, green to red and blue to yellow, respectively). $L$ * in 'Yellow' fruit peel increased from 15 to 45 DAP, in pulp the pattern was opposite decreasing as fruit ripened. This behavior was the same in 'Yellow' fruit regardless of where they were grown. For 'Gaúcho' melons grown in Brazil, $L$ * peel values decreased from 15 to 35 DAP then increased as fruit reached 45 DAP. $L^{*}$ values of pulp declined throughout ripening. For 'Gaúcho' fruit grown in Canada, L* peel values increased as ripening took place and on pulp they increased from 15 to 25 DAP and decreased until ripe stage (Supplementary Fig. 2).

Coordinates on the $a^{\star}$ axis for peel and pulp increased in 'Yellow' melons (Brazil and Canada), results for $b^{\star}$ increased throughout ripening for peel and slightly decreased for pulp. Hue angle $\left(\mathrm{H}^{\circ}\right)$ declined slightly as fruits ripened (Supplementary Fig. 2).

Results for the coordinates on the $a^{\star}$ axis in 'Gaúcho' (Brazil and Canada) melons increased for pulp and peel as maturation advanced having a slight decline in pulp results between 15 and 25 DAP in fruits grown in Canada. Coordinates on the $b^{*}$ axis also raised throughout ripening presenting the same behavior as the aforementioned results for $\mathrm{a}^{*}$ in pulp in fruits grown in Canada. $\mathrm{H}^{\circ}$ presented a declining pattern throughout ripening for both peel and pulp showing that the fruits have gone to greenish to reddish color as fruits ripened. Which is the phenotypic characteristic of fruits in this cultivar (Supplementary Fig. 2).

SSC in 'Yellow' melons (grown in Brazil and Canada) presented a slight increase from 15 to 25 D.A.P markedly increasing at 35 DAP reaching about $9{ }^{\circ}$ brix at 45 DAP, fruits grown in Brazil and Canada showed the same behavior for this variable. When it comes to $\mathrm{pH}$ for 'Yellow' fruits grown in both regions there was a slight decline from 15 to 35 DAP increasing again at 45 DAP. SSC of 'Gaúcho' fruit grown in Canada presented an increasing pattern from 15 to 45 DAP reaching about $10^{\circ}$ brix in mature fruit (45 DAP). In 'Gaúcho' melons grown in Brazil SSC decreased slightly at 25 DAP then increase to about $8^{\circ}$ brix at 45 DAP (Supplementary Fig. 3).

\section{Volatile profile of non-climacteric 'Yellow' and climacteric 'Gaúcho' melons}

The volatile compounds that changed significantly during melon development were specific to melon cultivar, with exception of (E)-2-octenal, 1 octen-3-one and 2-pentylfuran (Tables 3 and 4). A total of 120 metabolites were detected in non-climacteric 'Yellow' melons across the four developmental stages that 
had a relative abundance $>0.05 \%$ of the total volatile normalized area counts in at least one developmental stages (Supplementary Table S1). The most abundant chemical group was aldehydes with 32 volatiles (mainly hexanal, pentanal and heptanal), followed by 25 hydrocarbons, 14 ketones, 11 alcohols, 7 furans, 5 esters, (3 branched and 2 straight chained), 4 sulfur compounds, 3 monoterpenoids, 1 acid, 1 oxygenated hydrocarbon and 17 unknown compounds (Fig. 2; Supplementary table 4). A total of 30 of these compounds differed significantly $(P<0.1)$ among developmental stages (Supplementary Table 2). For this cultivar the total abundance of volatiles decreased as ripening took place. The total amount of volatiles detected in ripe fruit was half of that in fruit at 35 DAP and only $43 \%$ of that in fruit at 15 DAP (Supplementary Table 4).

In climacteric 'Gaúcho' melons, 143 volatile compounds were identified that had a relative abundance > $0.05 \%$ of the total volatile normalized area counts in at least one developmental stages (Supplementary table S2): 20 aldehydes, 38 esters (17 branched-chain and 21 straight-chain), 15 alcohols, 13 ketones, 13 hydrocarbons, 7 sulfur compounds, 4 nitrogen compounds, 3 oxygenated compounds, 2 acids, 2 furans, 1 terpenoid, 1 isoprenoid and 24 unknown compounds (Fig. 2, Supplementary Table 5). A total of 21 of these compounds were significantly $(P<0.1)$ different in their relative concentration among developmental stages (Supplementary Table 3). At 15 DAP the most abundant compounds in 'Gaúcho' melons were hexanal (21.1\%), 2-methylpropyl acetate (5.2\%) and pentanal (4.8\%) (Supplementary Table 5). At 25 DAP hexanal, pentanal and heptanal were the most abundant corresponding to $16.8 \%, 8.7$ $\%$ and $5.1 \%$ of the total volatiles (Supplementary Table 5). At 35 DAP the most expressed volatiles were 2methylbutyl acetate (16.7\%), butyl acetate (8.0\%) and 2-methylpropyl acetate (7.6\%) (Supplementary Table 5). In the 45 DAP melons, ethyl-2-methylbutanoate (11.3\%), ethyl butanoate (7.4\%) and 2methylbutyl acetate were the most abundant compounds. The total abundance of volatiles increased in fully ripe melons and was 8.6 times higher at the 45 DAP stage than in melons at 35 DAP and 18.6 times higher than in youngmelons at 15 DAP (Supplementary Table 5).

Comparing the non-climacteric and climacteric cultivars, 'Yellow' melon had higher numbers of aldehydes, hydrocarbons, and ketones during development while 'Gaúcho' melon had higher numbers of esters and alcohols (Fig. 2). The interactive effects of developmental stage and melon cultivar on fruit volatile composition were illustrated by principal component analysis (PCA), in which score 1 accounted for $41 \%$ and score 2 accounted for $31 \%$ of the variance of the data (Fig. 3). The PC1 score was associated with ripening of both melon cultivars with reduced concentrations of furans, acids, isoterpenoids and hydrocarbons being associated with ripe melons. The PC2 score was associated with differenced between ripe (45 DAP) 'Gaúcho' and 'Yellow' melons with higher concentrations of esters (branched and straight), aldehydes and alcohols associated with the former.

The comparison of the abundance of volatile compounds between stages and cultivars is shown in Supplementary table 3. Significant differences $(P<0.05)$ were observed in the esters methyl isobutanoate, methyl acetate, 2-methylpropyl propionate, methyl propionate and methyl butanoate; the aldehydes (E,Z)-2,6-nonadienal, 2-undecenal, (E)-2-nonenal, heptanal, octanal, and (E)-2-octenal; and the alcohol 1butanol. Most of these compounds had higher concentrations in ripe or ripening (35 and 45 DAP) 
climacteric 'Gaúcho' melons compared to non-climacteric 'Yellow' melons. Concentrations of the aldehyde $(E, Z)-2,6$-nonadienal was an exception to this being higher in immature (15 and 25 DAP) 'Yellow' melons than in 'Gaúcho' melons.

\section{Gene expression of key genes of VOC metabolism}

Seven key genes of VOC metabolism were selected to perform RT-qPCR analyses using CmRPS15 and CmRPL as reference genes (Fig. 4). The expression of these genes was tested on fruit at 35 and 45 DAP, the stages where fruit display a desirable ripe aroma. Associated with lipid metabolism, the 9lipoxygenase (CmLOX9) gene showed a trend of down regulation in 'Yellow' melons from 35 to 45 DAP fruit. Expression of $\mathrm{CmLOX9}$ at $35 \mathrm{DAP}$ was 2.2 times higher than in fruit at $45 \mathrm{DAP}$ although this difference was not significant. For 'Gaúcho' melons, this gene showed constant expression in the two ripening stages tested. When comparing non-climacteric with climacteric melons, the expression in 'Yellow' fruit was higher in both stages (04 times at 35 DAP and 8.2 times at 45 DAP) than that of 'Gaúcho' (Fig. 4). Another gene of this pathway responsible for 13-lipoxygenase (CmLOX18) decreased expression in both cultivars, being more pronounced in 'Gaúcho' melon (15.6 times). For 'Yellow' melons at 35 DAP the expression was 18.2 times lower than Gaúcho melons at the same stage (Fig. 4).

Associated with amino acid metabolism, branched chain amino transferase gene (CmBCAT1) expression increased 38.5 times in 'Gaúcho' melons from 35 to 45 DAP (Fig. 4). In non-climacteric 'Yellow' melon the expression of this gene increased only 2 times in 45 DAP fruit. When comparing these two cultivars at 35 DAP, the expression of CmBCAT1 was similar, whereas at 45 DAP the expression in 'Gaúcho' was notably higher than that of 'Yellow' melon (Fig. 4). The expression of aromatic amino transferase gene (CmArAT1) was considerably higher in fully ripe 'Gaúcho' melons being 48.5 times higher than in 'Yellow' melon fruit at the same stage. In 'Yellow' melons, expression of this gene did not differ significantly from 35 to 45 DAP. For 'Gaúcho' the expression of CmArAT1 at 45 DAP was 21 times higher than at 35 DAP (Fig. 4).

Three genes coding enzymes at the end of VOC biosynthesis pathways were evaluated, alcohol dehydrogenase $(\mathrm{CmADH})$, alcohol acyl transferase $(\mathrm{CmAAT})$ and pyruvate decarboxylase $(\mathrm{CmPDC})$. CmADH1 activity decreased as fruit ripened in both cultivars, being 1.8 and 4.3 times higher in 'Yellow' and 'Gaúcho' melons, respectively, at 35 DAP compared to fully ripe 45 DAP melons (Fig. 4). In contrast, the expression of $C m A A T 1$ was higher in 45 DAP than in 35 DAP fruit for both cultivars. However, only the increase activity for 'Gaúcho' melons (78 fold) was significant (Fig. 4). Considering both genotypes at the full ripe stage, 'Gaúcho' melons expression of CmAAT1 was 1.6 times higher than that of 'Yellow' melons and was not statistically significant. CmPDC1 activity increased slightly as fruit ripened. In 'Yellow' melons, expression was 3.7 times higher in 45 DAP ripe fruit than in 35 DAP fruit. In 'Gaúcho', the expression in ripe fruit was 13.3 times higher than in fruit at 35 DAP (Fig. 4).

\section{Correlation patterns of genes and metabolites}

Concentrations of VOCs that differed significantly across the four development stages (Supplementary Tables 2 and 3) were used to construct a correlation matrix (Fig. 5). The results showed positive 
correlations among most of the 'Yellow' melon volatile metabolites, being characterized by a decrease in concentration during ripening (Fig. 5, Supplementary Table 7). This pattern was observed in several aldehydes (Fig. 5, Supplementary Table 7). For 'Gaúcho' melons there was a high similarity among the esters. Propanal had significant negative correlations $(p<0.1)$ between the esters methylpropanoate, 2methylpropylpropanoate and methyl 2-methylpropanoate (Fig. 6, Supplementary Table S4). The alcohol metabolites were not grouped together by similar patterns of accumulation in 'Yellow' fruit, while in 'Gaucho' melons they had similar characteristics to esters (Fig. 5, Supplementary Table 8). Among the VOCs common to non-climacteric and climacteric melons, 1 octen-3-one and 2-pentylfuran were grouped in the same cluster in climacteric fruit and had a negative correlation with several metabolites, in contrast to the non-climacteric melon that presented only positive correlations (Fig. 5, Supplementary Table 8).

The correlation of gene expression versus volatile metabolite, gene expression versus gene expression and volatile metabolite versus volatile metabolite between 35 and 45 DAP fruit was also evaluated. The global analysis for 'Yellow' melon demonstrated one cluster with several aldehydes, furans, alcohols and the $\mathrm{CmLOX18}$ gene that showed a positive correlation (Fig. 6). Another cluster for this cultivar was represented by $C m B C A T 1, C m P D C 1, C m A A T 1$ with negative correlations with most VOCs (Fig. 6). For 'Gaúcho' melon the profile was characterized by a cluster of positive correlation compounds between CmArAT1, CmBCAT1, CmAAT1 and some several ketones. The opposite occurred with the expression of $\mathrm{CmADH} 1$ and $\mathrm{CmLOX18}$ genes that were downregulated during development while several VOCs increased in concentration (Fig. 6).

When considering lipid metabolism, cyclobut-1-enylmethanol, octanal, 2-methyl-3-pentanone and Z-4tridecene were the metabolites related to decreased activity of $C m L O X 9$ that presented a significant $(\mathrm{p}<$ 0.1) positive correlation for 'Yellow' melons (Fig. 6, Supplementary Table 9). There was no significant correlation between the VOCs and CmLOX9 gene expression in 'Gaúcho' melon. CmLOX18 had a significant $(p<0.1)$ positive correlation with octanal, pentanal, 2-methyl-3-pentanone, 1-octen-3-one, 2methylundecane-2-thiol, 1-heptene, Z-4-tridecene and pentyloxirane in the non-climacteric cultivar (Fig. 6, Supplementary Table 10). In climacteric fruit this gene did not present a significant correlation with the metabolites, but there was a relationship of its activity with the $\mathrm{CmADH} 1$ gene in this type of melon (Fig. 6, Supplementary Table 10).

In the amino acid pathway, although $C m B C A T 1$ had a low expression in 'Yellow' melons, it showed a significant $(p<0.1)$ negative correlation with pentanal, 1-octen-3-one, 2-methylundecane-2-thiol, 1-heptene and pentyloxirane. In contrast, 'Gaúcho' melons had a significant $(p<0.1)$ positive correlation between the gene and several alcohols, aldehydes and ketones (Fig. 6, Supplementary Table 10). The gene CmArAT1 only showed a correlation with cyclobut-1-enylmethanol synthesis in 'Yellow' melon, and in 'Gaúcho' there was a significant positive correlation with ketones and alcohols (Fig. 6, Supplementary Table 9).

At the end of VOC biosynthesis in non-climacteric fruit there was a strong significant $(p<0.1)$ negative correlation of CmAAT1 with most VOCs (Fig. 6, Supplementary Table 9). In climacteric fruit the correlation profile was opposite for $\mathrm{CmADH1}$ and $\mathrm{CmAAT1}$ (Fig. 6, Supplementary Table 10). The increased 
expression of CMPDC1 in 'Yellow' melon was related to the decrease of benzaldehyde, hexanal, 2methylfuran and heptane concentration, while for 'Gaúcho' melon there was a correlation with the increase of several aldehydes (Fig. 6, Supplementary Table 9).

\section{Discussion}

\section{Phenotypic characterization and metabolite profile of non- climacteric and climacteric melons}

Fruit development and ripening is a complex physiological process and involves many biochemical pathways that determine the quality of the fruit such as flavor (White, 2000). The chemical profiling of aroma is determined by specific combinations and proportions of volatile compounds, with the lipid and amino acid pathways having the greatest influence on this characteristic (Schwab et al. 2008; Gonda et al. 2010; Pott et al. 2019).

In addition, there are two types of fruit ripening, climacteric and non-climacteric, which have distinct regulatory mechanisms in determining organoleptic properties (McMurchie et al. 1972). Melon is an important species to study these differences because it presents both phenotypes, having climacteric cultivars that are generally more aromatic having esters as the most prominent volatiles, while the nonclimacteric cultivars are mostly non-aromatic (Portnoy et al 2008; Ezura e Owino 2008; Pech et al, 2008; Burger et al. 2006). Previous studies have reported the chemical characteristic of aroma in climacteric 'Dulce', 'Vendrantais' and non-climacteric 'Piel de Sapo' cultivars, as well as many others (Obando-Ulloa et al. 2008; Chen et al. 2016; Spadafora et al. 2019). However, this is the first study that presents an integrative analysis of metabolomics and gene expression of biochemical pathways related to volatile compound synthesis of non-climacteric ('Yellow') and climacteric ('Gaúcho') melons. Furthermore, the results of this study provide knowledge about the first steps to volatile biosynthesis, which is little explored; Previous studies mainly focused on the last steps that involve alcohol dehydrogenase and alcohol acetyltransferase (Flores et al. 2002; El-Sharkawy et al. 2005; Manríquez et al. 2006; Chen et al. 2016; Peng et al. 2020).

In the phenotypic characterization of climacteric and non-climacteric cultivars the colorimetric results showed similar behavior of hue angle for peel and pulp in 'Yellow' melon grown in Brazil and Canada as well as to those found by Schemberger et al.(Schemberger et al. 2020). For 'Gaúcho' melons, a few differences between melons grown in Brazil and Canada were observed, being the hue angle of the melon peel of 15 and 25 DAP melons and in the melon pulp of 35 and 45 DAP melons. For both cultivars there was a decrease in this parameter, but for 'Yellow' melon this was more subtle when compared to 'Gaucho' melon.

Color results demonstrate that 'Gaúcho' melons tend to be orange while 'Yellow' melons expressed a yellowish tone (MCLELLAN et al. 1995). The SSC increased during maturation while slight changes in $\mathrm{pH}$ occurred for both cultivars grown in Canada and Brazil. The SSC was a little higher in 45 DAP 'Gaúcho' 
melons compared to 'Yellow' melons and had minor variation in $\mathrm{pH}$, which correspond with previous studies of non-climacteric and climacteric melons (Saladié et al. 2015).

SPME-GC-MS technology was used to analyze the metabolomic differences between the stages and type of ripening in melons. The results showed that the variation in VOC concentrations during development is specific for non-climacteric and climacteric melons. This indicates that different pathways are activate in 'Yellow' and 'Gaucho' melons and some of which are ethylene-dependent. This is consistent with studies by Pech et al. (1999) that reported some aroma compounds, mainly esters, accumulate in response to ethylene metabolism. A new study on fruit ripening demonstrates this close relationship between ethylene and VOC formation when cold-triggered ripening, instead of the ethylenetriggered one, in climacteric kiwifruits do not set-off aroma compound formation (Mitalo et al. 2019).

The total amount of volatiles detected was higher in ripe 'Gaucho' melons than in 'Yellow' melons. For 'Yellow' melons, most of the volatiles detected were aldehydes, hydrocarbons, ketones, and alcohols. For 'Gaúcho' melons, esters, aldehydes, and alcohols dominated. These results are similar to those found in several comparative studies between climacteric and non-climacteric melons that also observed a greater amount of total volatiles in climacteric fruit, as well as a greater amount of esters, which are in general, the compounds responsible for the typical sweet and fruity aroma of climacteric melons (Gonda et al. 2016). In contrast, non-climacteric melons had greater amounts of alcohols and aldehydes (Shalit et al. 2001; El-Sharkawy et al. 2005; Gonda et al. 2016).

The PCA also demonstrated a strong positive association of 45 DAP 'Gaúcho' melons with esters (Fig. 3). The volatile metabolite versus volatile metabolite correlation and VOC concentration analyses during maturation demonstrated that there is a suppression of synthesis of most volatiles in 'Yellow' melon that can explain the non-aromatic characteristic of the non-climacteric phenotype. In contrast, 'Gaúcho' melons had a strong increase in esters and alcohol compounds due to its climacteric ripening (Bauchot et al. 1998; Bapat et al. 2010).

\section{Lipid metabolism}

Lipid metabolism is an important route in the determination of aroma composition of fruits. The main enzymes involved include the lipoxygenases (LOXs) that transform polyunsaturated fatty acids, such as linoleic acid and linolenic acid, into hydroperoxides (Andreou and Feussner 2009). In melon, there are 18 genes that code for these enzymes (CmLOX01-18), but only a few have a role in determining aroma traits (Zhang et al., 2013; Tang et al. 2015). In our study we evaluated two genes CmLOX9 and CmLOX18 as well as the metabolites related to the activity of the enzyme encoded by them. Expression of $\mathrm{CmLOX9}$ decreased from 35 DAP to 45 DAP in 'Yellow' melons as the fruit ripened. Similar results were found in RNA-Seq analysis of 'Yellow' melon, where expression of the CmLOX9 gene was higher in 10 DAP than 40 DAP melons (Schemberger et al. 2020). In 'Gaúcho' melons, the expression of this gene remained relatively constant at 35 DAP and 45 DAP and was lower than expression in 'Yellow' melons at both stages. 
Zhang et al. (Zhang et al. 2010) observed the expression of this gene in fruits treated to verify its dependence on ethylene and maturation and found that $C m L O X 9$ decreases expression in the presence of ethylene, as well as is not affected under ethylene inhibitors such as 1-methylcyclopropene (1-MCP), ethanol vapor or low temperatures. These results indicate that $C m L O X 9$ has more influence on nonclimacteric aroma determination. However, the contrary was found by Tang et al., (2015) who working with 18 LOX genes in four distinct melon cultivars, two aromatic (Makuwa Makino group cultivars Yu Meiren and Cui Bao) and two non-aromatic (conomon group, cultivar Shao Gua and flexuosus Naud group, cultivar Cai Gua) observed that the expression of this gene was higher in aromatic cultivars.

Vincenti et al., (2019) present the role of 9-LOXs in the formation of volatiles in plants such as (Z)-3nonenal, (E)-2-nonenal, $(E, Z)-2,6$-nonadienal and consequently their respective alcohols and esters. However, in our study no significant correlation with these compounds and CmLOX9 was detected. It is possible that another isoform may be acting on the synthesis of these metabolites.

CmLOX9 had a positive correlation in 'Yellow' melon with octanal $(R=0.89$ and $p=0.041)$, cyclobut-1enylmethanol $(R=0.93$ and $p=0.02)$, 2-methyl-3-pentanone $(R=0.922$ and $p=0.025)$ and $(Z)$-4-Tridecene $(R=0.92$ and $p=0.24)$, inferring the possibility this gene may be related to the production of these volatiles in 'Yellow' melon.

CmLOX18 showed a much lower expression in 'Yellow' compared to 'Gaúcho' melons at 35 DAP and no expression could be detected in this cultivar at 45 DAP. These results differ with those found by (Tang et al. 2015), where the expression of this gene in two aromatic cultivars Yu Meiren and Cui Bao (Makuwa Makino group) and the non-aromatic cultivar Cai Gua (flexuosus Naud group) were constant and significantly higher than in the aromatic cultivar Shao Gua (conomon group). In 'Gaúcho' melons it was possible to detect expression in ripe fruit, even though it was significantly lower than the results obtained at 35 DAP. Zhang et al.(Tang et al. 2015) have observed that the expression of this gene is up-regulated when ethylene is presente as well as it is down regulated in treatments that promove ripening delayal, indicating an importante role in the ripening processes of climacteric fruits such as 'Gaúcho' .

The 13-LOX (such as LOX18) enzymes act to form volatiles such as hexanal, (Z)-3-hexenal and (E)-2hexenal and their respective alcohols and esters in plants (Vincenti et al. 2019). Tang et al., (2015) reported that $\mathrm{CmLOX18}$ was a gene responsible for the formation of volatiles in melons. However, in our study, we did not identify any significant correlation between volatiles and CmLOX18transcription in 'Gaúcho' melons. In 'Yellow' melons there was a significant positive correlation with two aldehydes (octanal and pentanal), two ketones (2-methyl-3-pentanone and 1-octen3one), one sulfur compound (2methylundecane-2-thiol), two hydrocarbons (1-heptene and (Z)-4-tridecene) and one oxirane (pentyloxirane), but there was no correlation with hexanal. Interestingly, the same pattern of correlations with octanal, 2-methyl-3-pentanone and Z-4-tridecene was observed with CmLOX9 as with CmLOX18, indicating a strong influence of lipid metabolism in VOC formation that should be further investigated in non-climacteric melons. 
Tang et al. (Tang et al. 2015) suggests that there is a decrease in LOXs activity as algehydes levels come up, what can infer the downregulation we have noted for both CmLOX9 and CmLOX18 from 35 to 45 DAP.

\section{Amino acid metabolism}

VOCs derived from the catabolism of amino acids are present in both non-climacteric and climacteric cultivars and the biochemical reaction consist of a transamination followed by a decarboxylation. In climacteric melons, most compounds are esterified and are more abundant than in non-climacteric fruits, which have aldehydes and alcohols as the most expressive products (Gonda et al. 2016). The main amino acids involved in VOC synthesis are L-valine, L-leucine and L-isoleucine, which have a branched chain; and L-phenylalanine with an aromatic chain (Gonda et al. 2010). The first three have the transamination process mediated by the branched-chain amino transferases (BCATs) while the later by aromatic aminotransferases (ArATs) (Gonda et al. 2010).

There has previously been described in melons the correlation of the downregulation of $C m B C A T 1$, caused by 1-MCP treatment, and concomitant reduction in the activity of amino transferases enzymes related to the gene and subsequent decrease in fruit aroma content indicating this gene close relation to volatiles synthesis in an ethylene dependent ripening process(Li et al. 2016).In this study, CmBCAT1 expression increased as fruit ripened in both 'Yellow' and 'Gaúcho' melons, and expression was higher in ripe 'Gaúcho' melons. These results are similar to that of Gonda et al., (2010) who found a higher expression in ripe climacteric melons ('Dulce', 'Vedrantais', and 'Noy Yizre'el') than in non-climacteric ('Tam Dew', 'Rochet' and 'Piel De Sapo') ones. This pattern of expression was reflected in the metabolites formed (directly or indirectly) by the enzyme encoded by this gene. Most of the volatiles including several esters related to the activity of the enzyme coded by this gene had positive correlations with the gene activity in ripe 'Gaucho' melons.

Several studies have also indicated that climacteric melons tend to produce more total volatiles and including esters that result from the degradation of branched-chain amino acids (Schwab et al. 2008; Gonda et al. 2010). Considering the isoleucine and leucine catabolic pathway, significant correlations were observed between $C m B C A T 1$ expression and 2-methylbutanol $(R=0.95$ and $p=0.003)$. Considering valine metabolism, a significant correlation was observed between CmBCAT1 expression and 2methylpropylacetate $(R=0.84$ and $p=0.03)$. Several other compounds not described on this pathway by previous studies had a strong positive and significant correlation, including alcohols, aldehydes and esters. For 'Yellow' melons, there were significant negative correlations with pentanal $(R=-0.88$ and $p=$ 0.045), 1-octen-3-one ( $R=-0.83, P=0.07)$, 2-methylundecane-2-thiol $(R=-0.86, P=0.059), 1$-heptene $(R=-0.81, P=0.09)$ and pentyloxirane $(R=-0.98, P=0.002)$. ArATs degrade tyrosine and phenylalanine forming several different volatile compounds (Gonda et al. 2010; Lee and Facchini 2011). Gonda et al. (2010) demonstrated that the expression of CmArAT1 in melons is directly involved in the biosynthesis of acetaldehyde and its respective alcohol and esters, through the degradation of the amino acid phenylalanine. In this study, upregulation of the expression of CmArAT1 during ripening of climacteric 'Gaúcho' fruit were noted, while in 'Yellow' fruit this expression remained constant. The expression in ripe fruit was considerably higher in climacteric melons. Gonda et al., (2010) presented a similar pattern; in 
climacteric 'Dulce' melons the expression of this gene was higher in ripe fruit compared to 25 DAP fruit. Also higher activity of the enzyme coded by this gene in ripe climacteric fruit than in non-climacteric fruit was observed in the cultivars 'Tam Dew', 'Rochet' and 'Piel De Sapo'.

Confirming the hypothesis that these proteins are dependent on ethylene, in fruits treated with the ethylene antagonist 1-MCP, the expression of both genes CmArAT1 and CMBACT1 decreased profoundly, concomitantly with the decrease in the aminotransferases enzymatic activity. (Li et al. 2016)

Volatiles produced from the metabolism of phenylalanine were found not to correlate with this gene. However, other alcohols and esters were correlated with CmArAT's expression in 'Gaucho' melon.

\section{Final steps of VOCs biosynthesis}

In the final steps of lipid and amino acid metabolism two enzymes have crucial importance: alcohol dehydrogenase ( $A D H)$ and alcohol acetyltransferase (AAT). ADH are Z-binding enzymes that reversibly converts aldehydes into alcohols.At least 12 isoforms of $\mathrm{CmADH}$ are reported, with $\mathrm{CmADH} 1$ and $\mathrm{CmADH} 2$ being the most well characterized for the formation of volatiles in fruits.(Jin et al. 2016) While AAT promotes the esterification of alcohols (El-Sharkawy et al. 2005; Manríquez et al. 2006; Chen et al. 2016).

In melon, studies have reported an affinity of the isoform $\mathrm{CmADH1}$ for acetaldehyde (also known as ethanal), catalyzing its conversion into ethanol. The role of this enzyme in the conversion of butanal to butanol and hexanal to hexanol is also known, although it also acts, in a less expressive way with other aldehydes (Manríquez et al. 2006; Chen et al. 2016). In this study, $\mathrm{CmADH1}$ gene expression decreased as both 'Yellow' and 'Gaúcho' melons ripened from 35 DAP to 45 DAP. Manríquez et al.,(Manríquez et al. 2006) observed in wild 'Védrantais' melon (Cantalupensis group) that there is a significant increase in the expression of $\mathrm{CmADH} 1$ and $\mathrm{CmADH} 2$ during the peak of ethylene production (around $39 \mathrm{DAP}$ ), with a decrease in expression after the climatic peak, corroborating with the present study.

In climacteric and strongly aromatic melons (makuwa Makino group, cultivar Cai Hong) this gene presented an opposite behavior, increasing expression during maturation (Chen et al. 2016). However, for the enzymatic activity of ADH in this variety, it is observed that from 24 to 36 DAP there is an increase and a subsequent decrease, with peak activity in 32 DAP, similarly to what occurs with the gene expression for 'Yellow' melon and 'Gaúcho' (Chen et al. 2016) The same was observed in the climacteric 'Védrantais' melons of the Cantalupensis group, where there was also an upregulation until complete maturation,as ethylene concentration elevated by high respiration decreased (Manríquez et al. 2006).

The level of $\mathrm{CmADH1}$ transcripts in 'Yellow' melons did not have a significant correlation with the evaluated metabolites, indicating a limited involvement of this gene in the formation of alcohols in nonclimacteric melon fruit. On the other hand, in 'Gaúcho' melons there was a significant negative correlation of this gene with some alcohols including 1-butanol $(\mathrm{R}=-0.73$ and $\mathrm{P}=0.09)$, several esters, CmBCAT1 and CmAAT1. No correlation with aldehydes was observed. These results suggest involvement of $C m A D H 1$ in 
branched amino acid metabolism that also involves a high rate of conversion of alcohols into esters by CIAAT1.

The CmAAT1 gene was upregulated in both 'Yellow' and 'Gaúcho' melons during ripening. Considering these two melon genotypes at full ripeness, the expression of $C m A A T 1$ in non-climacteric fruit was significantly lower than that of climacteric fruit. The results obtained for 'Gaucho' were similar to those found by El-Sharkawy et al. (El-Sharkawy et al. 2005), where the expression of this gene was upregulated throughout ripening in climacteric 'Védrantais' melons (Cantalupensis group). Chen et al.,(Chen et al. 2016) confirms these results through the analysis of the enzymatic activity of ATT, where it is high and increases with the maturation in aromatic melon fruits (var. Makuwa Makino) and with a less evident increase in non-aromatic melon fruit (var. flexuosus Naud)Other authors also reported that the accumulation of volatile esters occurs in ripe fruit and that they were strongly correlated to ethylene production (Shalit et al. 2001; Flores et al. 2002). The expression of CmAAT1 was negatively regulated when in the presence of the ethylene antagonist (1-MCP) and in antisense ACC oxidase fruits(ElSharkawy et al. 2005) thus explaining why non-climacteric melons, the formation of esters is much lower than in climacteric fruit, which results in their classification as low aromatic or non-aromatic (Chen et al. 2016).

The CmAAT1 gene is related to the esterification of various alcohols such as 1-butanol, hexanol, heptanol, octanol, (Z)-2-hexen-1-ol, (E)-2-hexen-1-ol, (Z)-3-hexen-1-ol, (E)-3-hexen-1-ol, 2-methylpropanol, 2methylbutanol, 3-methylbutanol, and benzyl alcohol (El-Sharkawy et al. 2005). A positive correlation was found with 'Gaucho' melons for most metabolites evaluated including 2-methylbutanol $(\mathrm{R}=0.93$ and $\mathrm{P}=$ $0.005), 2$-methylbutanol $(R=0.847$ and $P=0.03)$ and several esters. These results suggest that the CmAAT1 gene is closely involved with the biosynthesis of these volatiles in climacteric melons. The relationship of $C m A A T 1$ with VOC formation have also been suggested by Nagashima et al. (Nagashima et al. 2021) working with Cantaloupe melons. For 'Yellow' melons, expression of this gene was positively correlated with several volatiles but the chemical groups consisted mainly of aldehydes, furans and hydrocarbons that are not directly related to the action of the enzyme encoded by this gene.

\section{Pyruvate decarboxylase pathway}

PDCs contribute to the formation of volatile compounds by catalyzing the transformation of a keto acid into an aldehyde (Sugimoto et al. 2011; Wang et al. 2019). Because this enzyme acts in the early stages of volatile formation, it has the potential to influence the formation of various volatiles derived from its substrates.

Moyano et al. (Moyano et al. 2004) have described PDC1 gene in strawberry to be involved in aroma formation. Zhu et al. (Zhu et al. 2020) working with bananas have also implied a PDC gene to be largely involved to aroma biosynthesis.

Wang et al. ${ }^{13}$ identified, in melon fruits, the gene function of $C M P D C 1$ by silencing this gene and measuring enzymatic activity. They pointed out that the activity of PDC1 was significantly low in fruit 
lined where the gene had been silenced. Furthermore with the gene silenced and enzymatically activity lowered there has been a massive decrease in the levels of the aromatic compound related to it.

In the aforementioned study seven substrates of the PDC1 Enzyme has been identified: pyruvate, 2oxobutanoate, 2-oxopentanoate, 2-oxohexanoate, ketoisocarprotate, ketomethylvalerate, and ketoisovalerate. The results of the present study showed a constant expression of CmPDC1 throughout ripening of 'Yellow' melons and an upregulation during ripening of 'Gaúcho' melons. CmPDC1 expression had a positive correlation with ( $E$ )-2-octenal $(R=0.89 P=0.02)$, ( $E$-2-2-nonenal $(R=0.87 P=0.02)$ and heptanal $(R=0.88 \mathrm{P}=0.02)$ in climacteric 'Gaúcho' fruit, which corroborates with aldehyde synthesis by the $C m P D C 1$ gene(Wang et al. 2019). This increase in CmPDC1 expression accompanies CmAAT1 activity to synthesize esters in the ripening melons.

\section{Conclusions}

Aroma plays an important role in determining organoleptic properties of fruit that influence consumption and demand. In our study we described an integrated metabolomics and gene expression analyses during fruit development of 'Yellow' and 'Gaucho' melons. The lipid pathway was primarily expressed in non-climacteric 'Yellow' fruit aroma formation, in that almost all metabolites decreased during maturation explaining the non-aromatic characteristic of this cultivar. In climacteric 'Gaúcho' melons the amino acid pathway was the primary one related to the biosynthesis of esters, which has been described in previous studies. The branched amino acid pathway correlated with $C m A D H 1$ and $C m A A T 1$ expression demonstrating integration between them. In addition, CmPD1 contributes to the formation of aldehydes in the beginning of the pathway. Thus these results open new perspectives to further explore the mechanisms of VOC formation in melons.

\section{Abbreviations}

DAP - Days after pollination

VOC - Volatile organic compounds

LOX - Lypoxigenase

$A A T$ - Alcohol acyl trasferade

$A D H-A l c o h o l ~ d e h y d r o g e n a s e$

$P D C$ - Pyruvate decarboxylase

BCAT - Branched-chain amino transferase

ArAT - Aromatic amino transferase 


\section{Declarations}

\section{Acknowledgements}

This research is supported by CAPES (Coordenação de Aperfeiçoamento de Pessoal de Nível Superior).

\section{Conflict of interest}

The views, opinions, and/or findings contained in this article are those of the authors. The authors declare no conflicts of interest.

\section{References}

Andreou A, Feussner I (2009) Lipoxygenases-structure and reaction mechanism. Phytochemistry 70:1504-1510

Bapat VA, Trivedi PK, Ghosh A, Sane VA, Ganapathi TR, Nath P (2010) Ripening of fleshy fruit: Molecular insight and the role of ethylene. Biotechnol. Adv.

Bauchot AD, Mottram DS, Dodson AT, John P (1998) Effect of Aminocyclopropane-1-carboxylic Acid Oxidase Antisense Gene on the Formation of Volatile Esters in Cantaloupe Charentais Melon (Cv. Védrandais). J Agric Food Chem. https://doi.org/10.1021/jf980692z

Bissacotti AP, Londero PMG (2017) Catálogo de sementes crioulas: resgate e valorização da agrobiodiversidade para garantir a segurança alimentar. Discip Sci Saúde 18:381-387

Chen H, Cao S, Jin Y, Tang Y, Qi H (2016) The Relationship between CmADHs and the Diversity of Volatile Organic Compounds of Three Aroma Types of Melon (Cucumis melo). Front Physiol. https://doi.org/10.3389/fphys.2016.00254

El-Sharkawy I, Manríquez D, Flores FB, Regad F, Bouzayen M, Latché A, Pech JC (2005) Functional characterization of a melon alcohol acyl-transferase gene family involved in the biosynthesis of ester volatiles. Identification of the crucial role of a threonine residue for enzyme activity. Plant Mol Biol. https://doi.org/10.1007/s11103-005-8884-y

FAO (2018) FAOSTAT: Statistical database. FAOSTAT Stat. database.

Feussner I, Wasternack C (2002) The lipoxygenase pathway. Annu. Rev. Plant Biol.

Flores F, El Yahyaoui F, De Billerbeck G, Romojaro F, Latché A, Bouzayen M, Pech JC, Ambid C (2002) Role of ethylene in the biosynthetic pathway of aliphatic ester aroma volatiles in Charentais Cantaloupe melons. J Exp Bot. https://doi.org/10.1093/jexbot/53.367.201 
Gonda I, Bar E, Portnoy V, Lev S, Burger J, Schaffer AA, Tadmor Y, Gepstein S, Giovannoni JJ, Katzir N, Lewinsohn E (2010) Branched-chain and aromatic amino acid catabolism into aroma volatiles in Cucumis melo L. fruit. J Exp Bot. https://doi.org/10.1093/jxb/erp390

Gonda I, Burger Y, Schaffer AA, Ibdah M, Tadmor Y, Katzir N, Fait A, Lewinsohn E (2016) Biosynthesis and perception of melon aroma. In: Biotechnology in Flavor Production

Jin Y, Zhang C, Liu W, Tang Y, Qi H, Chen H, Cao S (2016) The alcohol dehydrogenase gene family in melon (Cucumis melo L.): bioinformatic analysis and expression patterns. Front Plant Sci 7:670

Kong Q, Yuan J, Gao L, Zhao S, Jiang W, Huang Y, Bie Z (2014) Identification of suitable reference genes for gene expression normalization in qRT-PCR analysis in watermelon. PLoS One. https://doi.org/10.1371/journal.pone.0090612

Lee EJ, Facchini PJ (2011) Tyrosine aminotransferase contributes to benzylisoquinoline alkaloid biosynthesis in opium poppy. Plant Physiol. https://doi.org/10.1104/pp.111.185512

Li Y, Qi H, Jin Y, Tian X, Sui L, Qiu Y (2016) Role of ethylene in biosynthetic pathway of related-aroma volatiles derived from amino acids in oriental sweet melons (Cucumis melo var. makuwa Makino). Sci Hortic (Amsterdam) 201:24-35

Livak KJ, Schmittgen TD (2001) Analysis of relative gene expression data using real-time quantitative PCR and the 2- $\triangle \triangle C T$ method. Methods. https://doi.org/10.1006/meth.2001.1262

Manríquez D, El-Sharkawy I, Flores FB, El-Yahyaoui F, Regad F, Bouzayen M, Latché A, Pech JC (2006) Two highly divergent alcohol dehydrogenases of melon exhibit fruit ripening-specific expression and distinct biochemical characteristics. Plant Mol Biol. https://doi.org/10.1007/s11103-006-0040-9

Mclellan MR, Lind LR, Kime RW (1995) Hue Angle Determinations and Statistical Analysis For Multiquadrant Hunter L,a,b DATA. J Food Qual. https://doi.org/10.1111/j.1745-4557.1995.tb00377.x

McMurchie EJ, McGlasson WB, Eaks IL (1972) Treatment of fruit with propylene gives information about the biogenesis of ethylene. Nature 237:235-236

Mitalo OW, Tokiwa S, Kondo Y, Otsuki T, Galis I, Suezawa K, Kataoka I, Doan AT, Nakano R, Ushijima K, Kubo Y (2019) Low temperature storage stimulates fruit softening and sugar accumulation without ethylene and aroma volatile production in kiwifruit. Front Plant Sci.

https://doi.org/10.3389/fpls.2019.00888

Moyano E, Encinas-Villarejo S, López-Ráez JA, Redondo-Nevado J, Blanco-Portales R, Bellido ML, Sanz C, Caballero JL, Muñoz-Blanco J (2004) Comparative study between two strawberry pyruvate decarboxylase genes along fruit development and ripening, post-harvest and stress conditions. Plant Sci 166:835-845 
Nagashima Y, He K, Singh J, Metrani R, Crosby KM, Jifon J, Jayaprakasha GK, Patil B, Qian X, Koiwa H (2021) Transition of aromatic volatile and transcriptome profiles during melon fruit ripening. Plant Sci 304:110809

Obando-Ulloa JM, Moreno E, García-Mas J, Nicolai B, Lammertyn J, Monforte AJ, Fernández-Trujillo JP (2008) Climacteric or non-climacteric behavior in melon fruit: 1. Aroma volatiles. Postharvest Biol Technol 49:27-37

Paris HS, Tadmor Y, Schaffer AA (2016) Cucurbitaceae Melons, Squash, Cucumber. In: Encyclopedia of Applied Plant Sciences

Pech JC, Guis M, Botondi R, Ayub R, Bouzayen M, Lelievre JM, Yahyaoui F El, Latche A (1999) Ethylenedependent and ethylene-independent pathways in a climacteric fruit, the melon. In: Biology and biotechnology of the plant hormone ethylene II. Springer, pp 105-110

Peng B, Xu J, Cai Z, Zhang B, Yu M, Ma R (2020) Different Roles of the Five Alcohol Acyltransferases in Peach Fruit Aroma Development. J Am Soc Hortic Sci. https://doi.org/10.21273/jashs04951-20

Pitrat M, Hanelt P, Hammer K (2000) Some comments on infraspecific classification of cultivars of melon. In: Acta Horticulturae

Pott DM, Osorio S, Vallarino JG (2019) From central to specialized metabolism: An overview of some secondary compounds derived from the primary metabolism for their role in conferring nutritional and organoleptic characteristics to fruit. Front. Plant Sci.

Saladié M, Cañizares J, Phillips MA, Rodriguez-Concepcion M, Larrigaudière C, Gibon Y, Stitt M, Lunn JE, Garcia-Mas J (2015) Comparative transcriptional profiling analysis of developing melon (Cucumis melo L.) fruit from climacteric and non-climacteric varieties. BMC Genomics. https://doi.org/10.1186/s12864015-1649-3

Schemberger MO, Stroka MA, Reis L, De Souza Los KK, De Araujo GAT, Sfeir MZT, Galvão CW, Etto RM, Baptistão ARG, Ayub RA (2020) Transcriptome profiling of non-climacteric "yellow" melon during ripening: Insights on sugar metabolism. BMC Genomics. https://doi.org/10.1186/s12864-020-6667-0

Schwab W, Davidovich-Rikanati R, Lewinsohn E (2008) Biosynthesis of plant-derived flavor compounds. Plant J.

Shalit M, Katzir N, Tadmor Y, Larkov O, Burger Y, Shalekhet F, Lastochkin E, Ravid U, Amar O, Edelstein M, Karchi Z, Lewinsohn E (2001) Acetyl-CoA: Alcohol acetyltransferase activity and aroma formation in ripening melon fruits. J Agric Food Chem. https://doi.org/10.1021/jf001075p

Spadafora ND, Cocetta G, Cavaiuolo M, Bulgari R, Dhorajiwala R, Ferrante A, Spinardi A, Rogers HJ, Müller CT (2019) A complex interaction between pre-harvest and post-harvest factors determines fresh-cut melon quality and aroma. Sci Rep 9:1-15 
Sugimoto N, Daniel Jones A, Beaudry R (2011) Changes in free amino acid content in "Jonagold" apple fruit as related to branched-chain ester production, ripening, and senescence. J Am Soc Hortic Sci. https://doi.org/10.21273/jashs.136.6.429

Tang Y, Zhang C, Cao S, Wang X, Qi H (2015) The effect of CmLOXs on the production of volatile organic compounds in four aroma types of melon (Cucumis melo). PLoS One.

https://doi.org/10.1371/journal.pone.0143567

Team RC (2010) R Development Core Team, 2014. R a Lang Environ Stat Comput

Vincenti S, Mariani M, Alberti JC, Jacopini S, de Caraffa VBB, Berti L, Maury J (2019) Biocatalytic synthesis of natural green leaf volatiles using the lipoxygenase metabolic pathway. Catalysts

Wang M, Zhang L, Boo KH, Park E, Drakakaki G, Zakharov F (2019) PDC1, a pyruvate/a-ketoacid decarboxylase, is involved in acetaldehyde, propanal and pentanal biosynthesis in melon (Cucumis melo L.) fruit. Plant J. https://doi.org/10.1111/tpj.14204

Wei T, Simko V, Levy M, Xie Y, Jin Y, Zemla J (2017) Package 'corrplot.' Statistician 56:e24

White PJ (2002) Recent advances in fruit development and ripening: An overview. J Exp Bot. https://doi.org/10.1093/jxb/erf105

Zhang B, Shen JY, Wei WW, Xi WP, Xu CJ, Ferguson I, Chen K (2010) Expression of genes associated with aroma formation derived from the fatty acid pathway during peach fruit ripening. J Agric Food Chem. https://doi.org/10.1021/jf100172e

Zhu X, Song Z, Li Q, Li J, Chen W, Li X (2020) Physiological and transcriptomic analysis reveals the roles of 1-MCP in the ripening and fruit aroma quality of banana fruit (Fenjiao). Food Res Int 130:108968

\section{Figures}



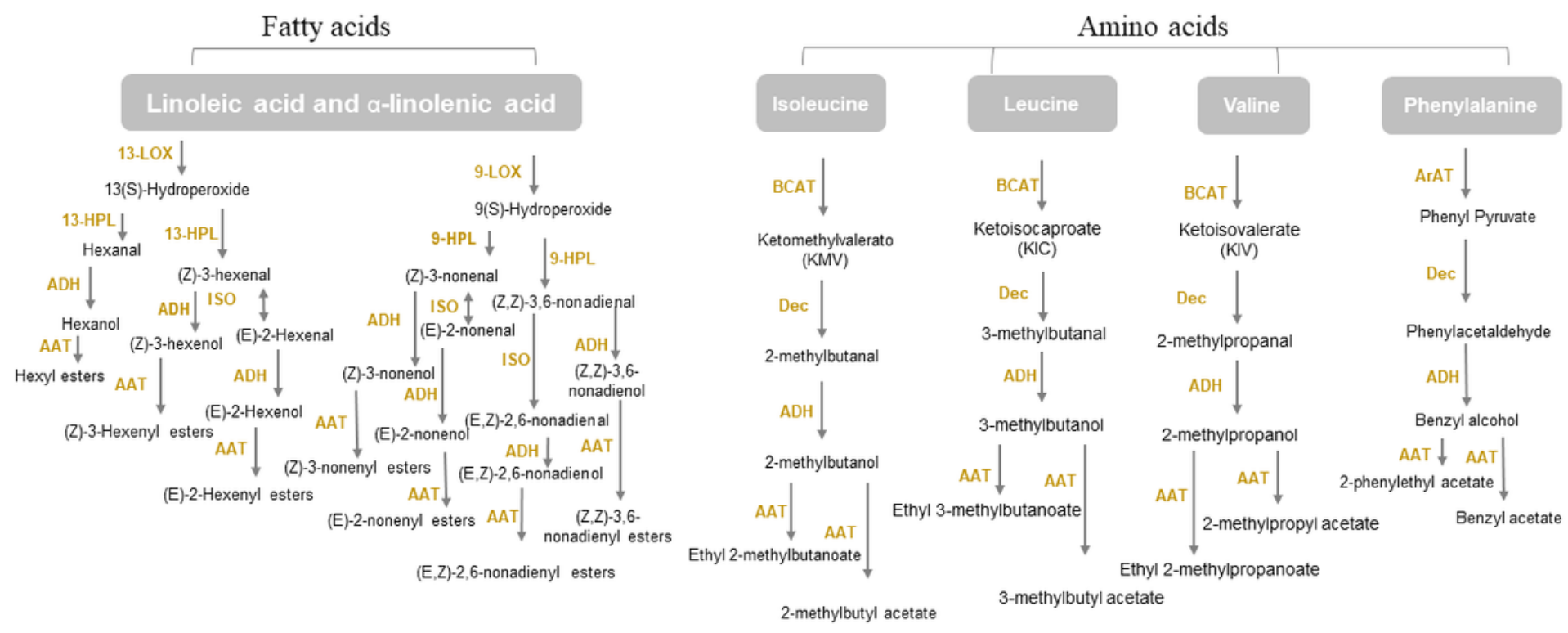

\section{Figure 1}

Biosynthetic routes for lipid and amino acid catabolism in plants. In yellow beside the arrows are the enzymes known to act upon the precursors to form the following volatile. Adapted from Gonda et al., (2010) and Vincenti et al., (2019). 


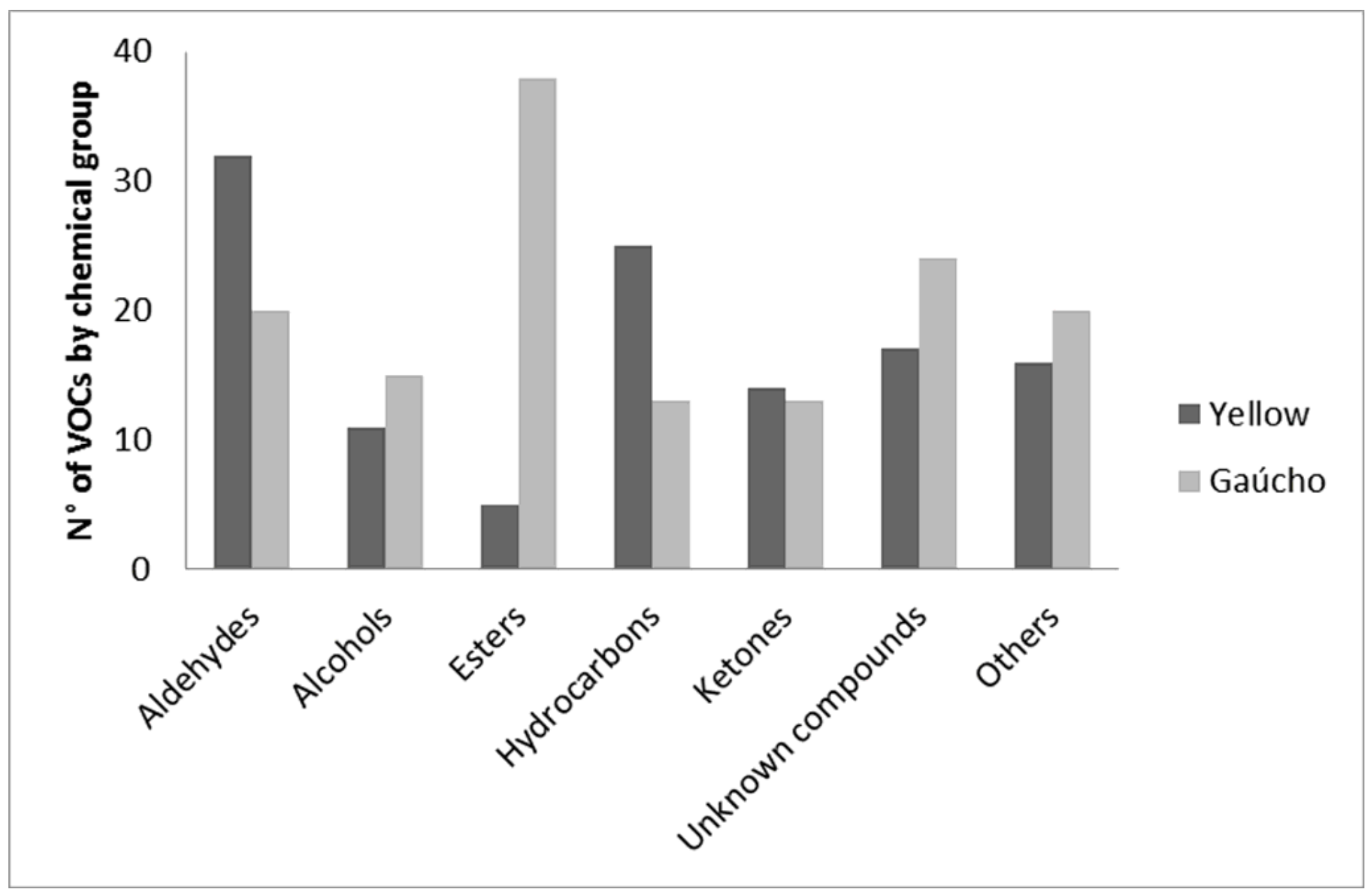

Figure 2

VOC chemical groups found in 'Yellow' and 'Gaúcho' melons through SPME-GC-MS analysis. 
pcagrpVolMelon17, 1 PCA: Score 1 vs 2

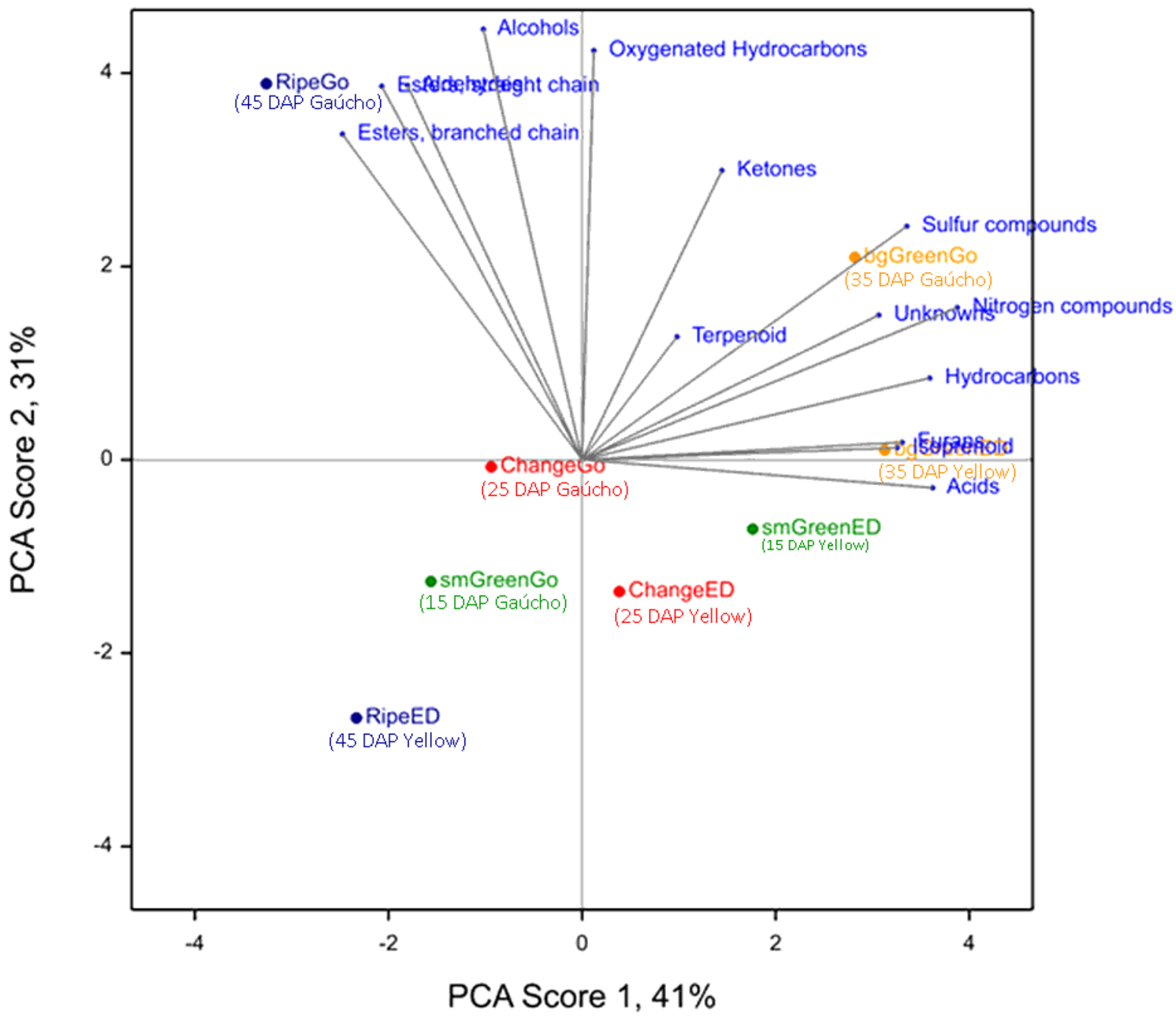

Figure 3

Principal component analysis (PCA) biplot for the first two principal component (PC) scores for 13 variables (acids, alcohols, aldehydes, straight-chain esters, branched-chain esters, oxygenated hydrocarbons, furans, hydrocarbons, ketones, isoterpenoid, terpenoid, sulfur compounds, nitrogen compounds) observed in 'Yellow' and 'Gaúcho' melons at four development stages (15DAP, 25 DAP, 35 DAP and 45 DAP). 

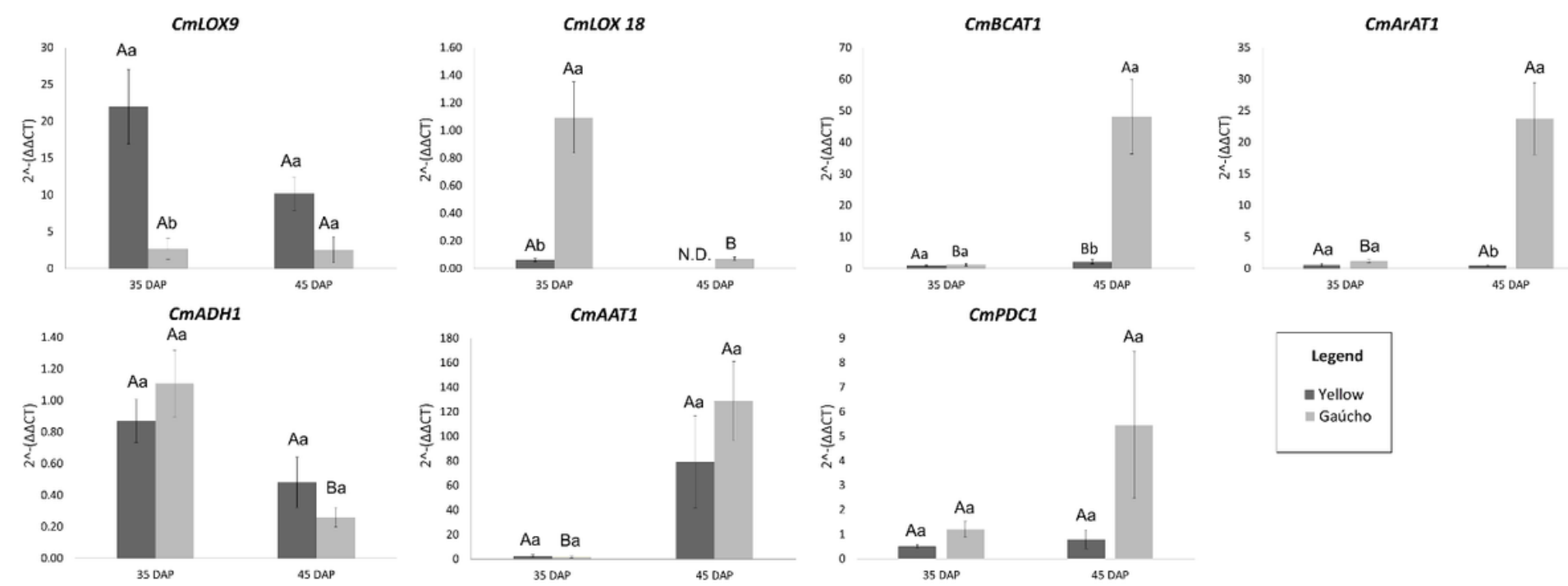

\section{Figure 4}

The relative mRNA expression of genes of VOC metabolism was determined by $2-\Delta \Delta \mathrm{Ct}$ (Livak and Schmittgen, 2001). Results are expressed as mean \pm SEM and significance of different developmental stages (15 DAP, 25 DAP, 35 DAP, 45 DAP) as defined as by the Tukey test $(p \leq 0.05)$ after data normalization by the Box-Cox method. Different capital letters indicate significant differences among stages in the same cultivar. Different small case letters indicate significant differences among cultivars in the same ripening stage.

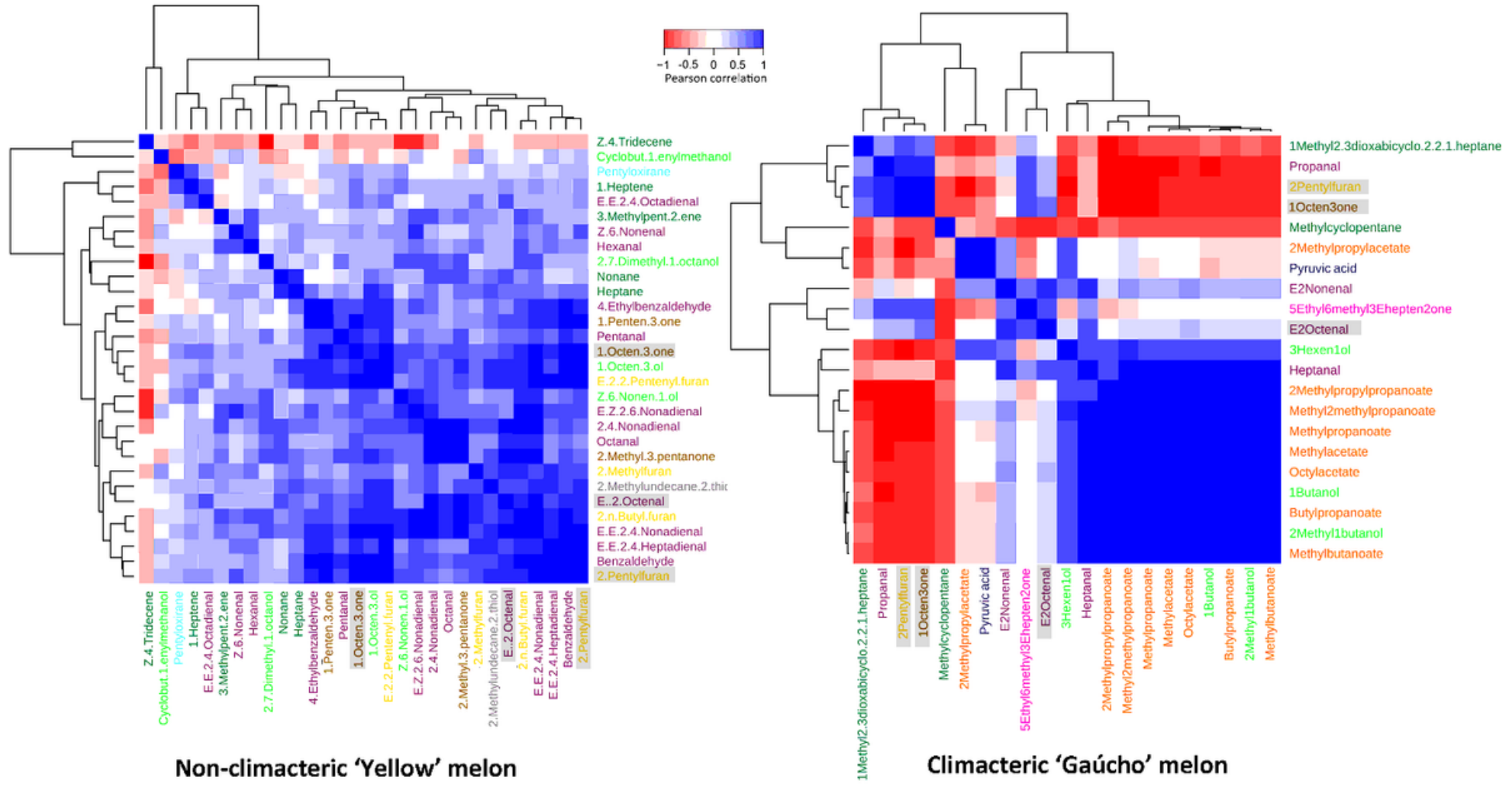

Figure 5 
Heatmap of metabolites versus metabolites correlation matrix of volatile metabolites that differed significantly $(P<0.1)$ during ripening (four stages) of climacteric and non-climacteric melon (Pearson coefficient). The positive and negative correlations are illustrated in the color key. The color of metabolite names indicated the chemical group. The purple color stands for aldehydes, light green for alcohols, dark green for alkanes, brown for ketones and orange for esters. Metabolites are listed based on a hierarchical cluster analysis with brackets to the left and top of the heatmaps indicating similarity.

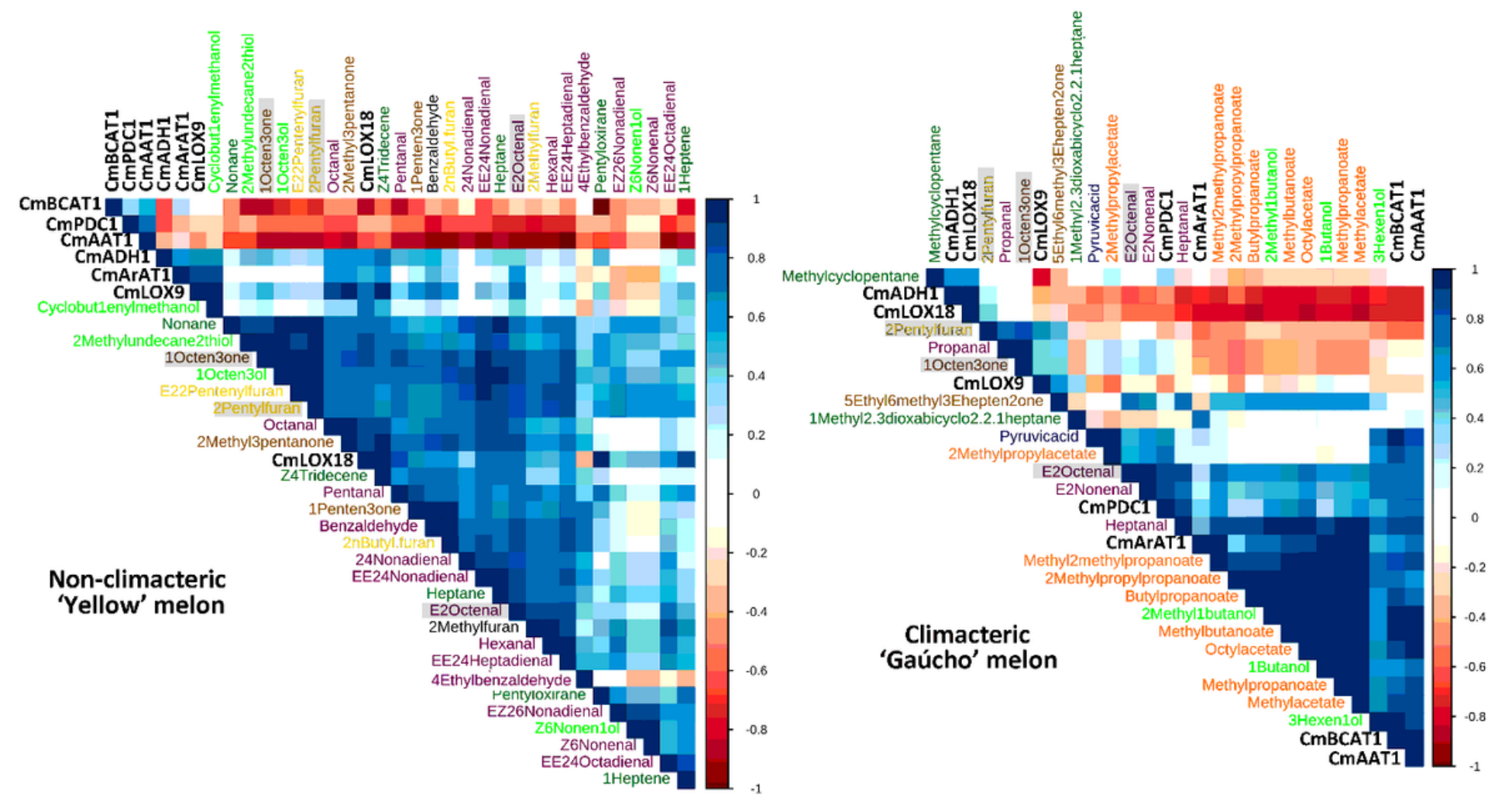

\section{Figure 6}

Correlation matrix of metabolites versus metabolites, gene versus gene expression and metabolites versus gene expression that were significant between 35 to 45 DAP stages in climacteric and nonclimacteric melon (Pearson coefficient). The positive and negative correlations are demonstrated in color key. The same name colors represent same chemical group. The highlight in grey are the metabolites that have variation during development and are common for both types of maturation. The purple color stands for aldehydes, light green for alcohols, dark green for alkanes, brown for ketones and orange for esters.

\section{Supplementary Files}

This is a list of supplementary files associated with this preprint. Click to download.

- SupplementaryfigureS1.tiff

- SupplementaryfigureS24.tiff 
- SupplementaryfigureS32.tiff

- SupplementaryfigureS43.tiff

- SupplementarytableS1.docx

- SupplementarytableS10.xlsx

- SupplementarytableS2.docx

- SupplementarytableS3.docx

- SupplementarytableS4.xIsx

- SupplementarytableS5.xIsx

- SupplementarytableS6.xIsx

- SupplementarytableS7.xIsx

- SupplementarytableS8.xlsx

- SupplementarytableS9.xlsx 